\title{
Numerical simulation of a new horizontal spray tower for sintering flue gas desulfurization
}

\author{
Wei Su*, Yi Xing**, Hongzhi Ma**, Rui Li*, Cunyi Song* and Zhensong Tong* \\ *School of Civil and Environmental Engineering, Beijing Key Laboratory of Resource-Oriented Treatment of Industrial Pollutants, University of \\ Science and Technology Beijing, Beijing 100083, China \\ **These authors contributed equally to this work and should be considered corresponding authors: xing_team@126.com,mhz527@sina.com
}

\begin{abstract}
The flow rate and temperature of the flue gas from a sintering machine can fluctuate in a wide range; thus, the follow-up desulfurization facility should be operated stably and maintained on-line. A new type of horizontal spray tower, which can achieve high efficiency with low pressure loss and easy maintenance, was invented by the University of Science and Technology Beijing. A 3D multiphase computational fluid dynamics (CFD) model of the horizontal spray tower was constructed with Fluent software to study the internal flow field and the reaction of the horizontal spray tower. The standard $\mathrm{k}-\xi$ model and the Eulerian-Lagrangian model were adopted in this study. Results show that the flow field in the spray tower can be numerically simulated utilizing the CFD technology. The inlet angle exerts an important effect on the flue gas flow field of the horizontal tower. When the first-order efficiency and the economic indicators are taken into account, an inlet angle of $75^{\circ}$ is recommended in the top inlet intake mode, whereas a $30^{\circ}$ inlet angle performs the best in the side inlet intake mode. The spray configuration exerts an important influence. When the spray cone angle is $110^{\circ}$ and the installation height is controlled at $0.8 \mathrm{~m}$ from the top surface, the smoke residence time is long, and the contact is sufficient. The results can provide theoretical support for the optimization of the structure of the spray tower.
\end{abstract}

Keywords: Sintering flue gas; horizontal spray tower; desulfurization; numerical simulation; spray arrangement.

\section{INTRODUCTION}

The problems of air pollution caused by industrial flue gases have attracted increasing attention, especially in the field of metallurgy. $\mathrm{SO}_{2}$ is not only an important source of acid rain but also an important precursor to haze (Song et al., 2009; Fan et al., 2017). Technologies for $\mathrm{SO}_{2}$ emission control have been developed for decades. Among these technologies, wet flue gas desulfurization has been widely used in the metallurgical and other industries (Wei et al., 2014; Liu et al., 2018). Wet desulfurization requires a desulfurizer with fast reaction speed, high desulfurization efficiency, and high utilization rate. However, the traditional vertical spray tower process has high system pressure loss and high construction and operation costs. Therefore, desulfurization facilities are difficult to maintain, and high desulfurization is difficult to keep (Nygaard et al., 2004; Marocco, 2010). A new horizontal spray desulfurization process was developed by the Environmental Engineering Center of University of Science and Technology Beijing. The technology has lower construction and operation costs than those of the traditional vertical spray desulphurization process but can yield high desulfurization efficiency with nonstop maintenance. The new horizontal spray tower (HST-FGD) is based on the original tower type. The desulfurization nozzles are mounted on the top wall of the tower. The injection direction of the nozzles can easily be adjusted to achieve multi-angle gas-liquid contact reaction and eliminate dead zone. In consideration of the need of frequent overhauls of nozzles in the wet process, a nozzle can be directly replaced at the top of the tower without entering the tower, thereby reducing the difficulty of maintenance. HST-FGD has run in a practical scale and has received an authorized invention patent. However, some aspects of this new technology need to be improved. Furthermore, the characteristics of the flue gas discharged by the sintering 
machine lead to wide fluctuations in the gas flow rate and temperature. Therefore, the following desulfurization facility is required to achieve high impact resistance, stable operation, and even on-line maintenance. Correspondingly, the entire desulfurization reaction process can be greatly influenced by the pressure and temperature of the flue gas. Therefore, the internal flow field and the reaction of the horizontal spray tower should be studied. Some studies (Wen et al., 2015; Calautit et al., 2014) constructed the model of the tower, in order to investigate the influence caused by different factors such as the inlet angle.

Also, optimizing studies need to be conducted to increase the desulfurization efficiency utilizing the model.

In this study, a model for the horizontal desulfurization spray tower was constructed by computational fluid dynamics (CFD) software (Du et al., 2010). The influences of the different inlet methods on flow field, pressure loss, flue gas residence time, and relative factors were studied. The results can provide guidance for a practical engineering design.

\section{CALCULATION PARAMETERS AND MATHEMATICAL MODEL}

\subsection{Model construction}

The structure of the horizontal spray tower is shown in Fig. 1. The tower is $26 \mathrm{~m}$ long, $5.4 \mathrm{~m}$ wide, and $9.8 \mathrm{~m} \mathrm{high}$. The slurry is $3.4 \mathrm{~m}$ in the tower. The amount of flue gas is $500,000 \mathrm{~m}^{3} / \mathrm{h}$. The nozzles are installed at the top of the tower, and the adsorption solution is sprayed from top to bottom. All of the 40 nozzles are divided into 5 groups evenly distributed at the top of the tower. The diameter of the gas inlet is $3.0 \mathrm{~m}$, whereas the outlet is $4.4 \mathrm{~m}$. An unstructured mesh is adopted in this case. The total number of grids is approximately 430,000. The inlet speed of the flue gas is 20 $\mathrm{m} / \mathrm{s}$, and the temperature is $400 \mathrm{~K}$. The outlet relative pressure of the flue gas is defined as $0 \mathrm{~Pa}$ compared with the atmosphere. The ratio of spray liquid to gas is 4.7 .

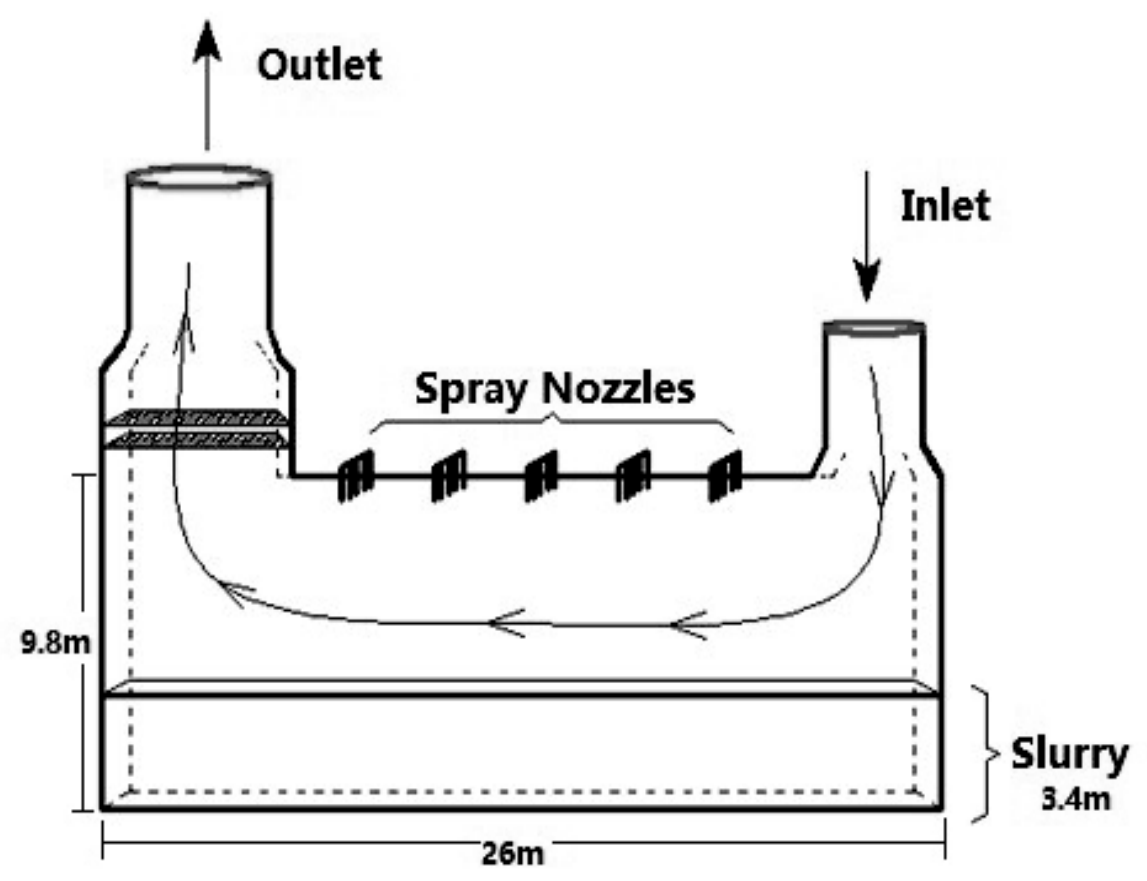

Figure 1. Structure of the horizontal spray tower. 


\subsection{Basic assumptions}

The following assumptions are made in constructing the model.

(1) The gas flow is incompressible. The effect of the heat transfer between the gas-liquid phase and the wall surface is negligible.

(2) The slurry inside the tower is defined as the wall. The droplets that fall onto the slurry surface will be trapped at once to stop them from affecting the flow field inside the tower.

(3) The droplets are regarded as rigid balls. The coalescence and breakup of the droplets are ignored. Therefore, the heat transfer is considered, whereas the evaporation of the droplet is neglected.

(4) The initial particle size distribution of the slurry droplets conforms to the Rosin-Rammler distribution. The distribution parameters, initial velocity of the flue gas, flow rate, and slurry flow rate are selected in accordance with the literature (Liang et al., 2007).

(5) The axes are set as shown in Fig. 2. The origin is in the lower middle of the top wall of the inlet, the $X$-axis is in the longitudinal direction of the tower, the $Z$-axis is in the transverse direction, and the $Y$-axis is in the vertical direction.

(6) The flue gas flow field is simulated with the Fluent software. The double equation model is the turbulence model. The Lagrangian discrete phase model is used to simulate the turbulent flow. The second order windward difference scheme is selected by the discrete equation. The SIMPLE algorithm is used to calculate the pressure coupling.

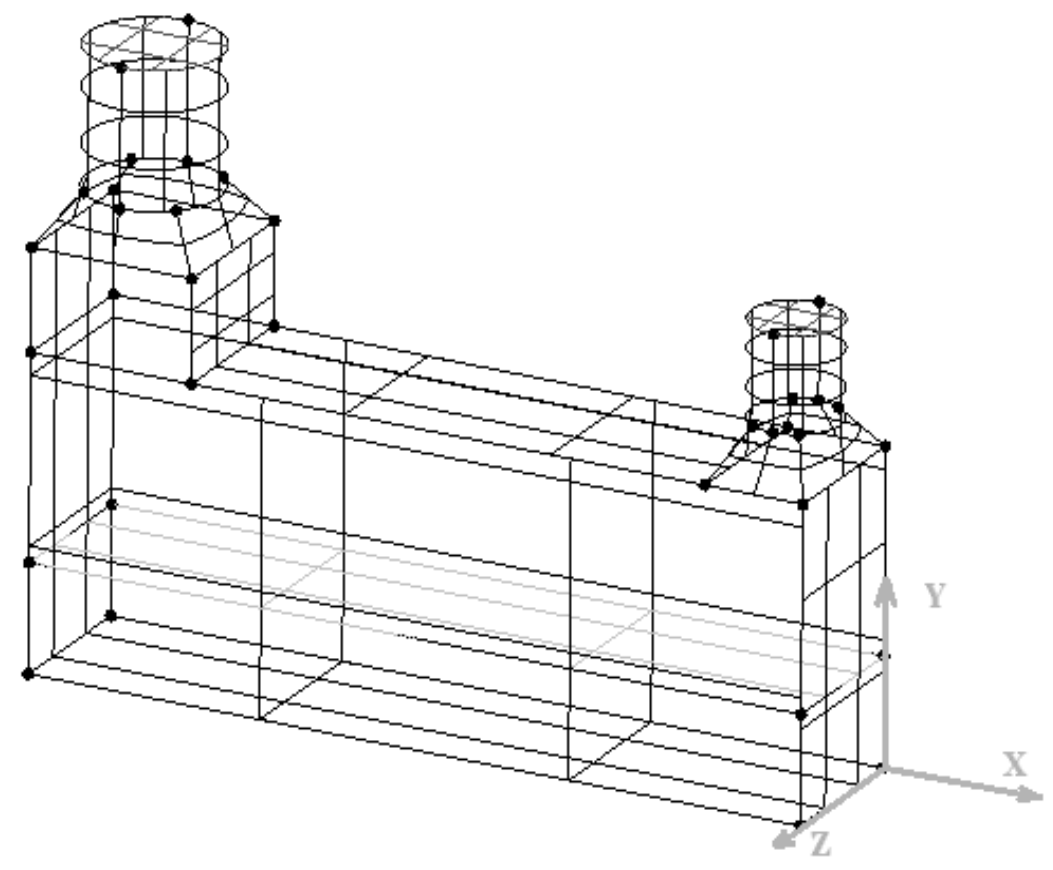

Figure 2. Schematic of the system coordinate system.

\subsection{Models}

After the assumptions and simplification have been made, two mathematical models are calculated in the numerical simulation of the flow field in the tower. The first model is for the flue gas, which occupies most of the volume in the flow field and is used as a continuous phase. The second model is for the droplets, which account for less than $10 \%$ of the volume of the total flow field and are applied as discrete phases (Zhou et al., 2005). 
(1) Gas flow field control equation

Smoke is considered the incompressible continuum of the main body; thus, the Euler method is used. Based on the given assumptions, the equation describing the continuity of the flow field for incompressible gases can be expressed as

$$
\operatorname{div}(\vec{u})=0 .
$$

The momentum conservative equations are

$$
\begin{gathered}
\frac{\partial(\rho u)}{\partial t}+\operatorname{div}(u \vec{u})=-\frac{\partial p}{\partial x}+\operatorname{div}(\mu \operatorname{grad}(u))+F_{x}, \\
\frac{\partial(\rho v)}{\partial t}+\operatorname{div}(v \vec{u})=-\frac{\partial p}{\partial y}+\operatorname{div}(\mu \operatorname{grad}(v))+F_{y}, \\
\frac{\partial(\rho w)}{\partial t}+\operatorname{div}(w \vec{u})=-\frac{\partial p}{\partial z}+\operatorname{div}(\mu \operatorname{grad}(w))+F_{z} .
\end{gathered}
$$

In Equations (1-2)-(1-4), $p$ is static pressure; $F_{x}, F_{y}$, and $F_{z}$ are the forces acting on the slurry droplet and gas phase flow field. Equations (1-2)-(1-4) can be treated as the Reynolds-averaged (time-averaged) Navier-Stokes equations.

The turbulence $k$ control equation is

$$
\frac{\partial(p k)}{\partial t}+\frac{\partial\left(p k u_{i}\right)}{\partial x_{i}}=\frac{\partial}{\partial x_{i}}\left[\left(\mu+\frac{\mu_{t}}{\delta_{k}}\right) \frac{\partial k}{\partial x_{j}}\right]+G_{k}-\rho \varepsilon .
$$

The turbulence dissipation rate $\varepsilon$ control equation is

$$
\frac{\partial(\rho \varepsilon)}{\partial t}+\frac{\partial\left(\rho \varepsilon u_{i}\right)}{\partial x_{i}}=\frac{\partial}{\partial x_{j}}\left[\left(\mu+\frac{\mu_{t}}{\delta_{\varepsilon}}\right) \frac{\partial \varepsilon}{\partial x_{j}}\right]+\frac{C_{1 \varepsilon} \varepsilon}{k} G_{k}-C_{2 \varepsilon} \rho \frac{\varepsilon^{2}}{k} .
$$

The value of $G_{k}$ in the Equations (1-5) and (1-6) is

$$
G_{k}=\mu_{t}\left\{2\left(\frac{\partial u_{i}}{\partial x_{i}}\right)^{2}+\left(\frac{\partial u_{i}}{\partial x_{j}}+\frac{\partial u_{j}}{\partial x_{i}}\right)^{2}\right\}
$$

The turbulent viscosity model is expressed as $\mu_{t}=\rho C_{\mu} \frac{k^{2}}{\varepsilon}$, and the values of the constants in the equations are $C_{1 \varepsilon}=1.44, C_{2 \varepsilon}=1.92, C_{\mu}=0.09, \delta_{k}=1.0$, and $\delta_{\varepsilon}=1.3$.

The energy equation is

$$
\frac{\partial}{\partial t}(\rho h)+\operatorname{div}(\rho u h)=\operatorname{div}\left(\frac{K}{c} \operatorname{divh}\right)+s .
$$

The first term on the right side of the equation includes the heat transfer and diffusion sections, and the viscous dissipation is included as a protected form in the second term. Sampling (inhalation) contains the user-defined chemical reaction, heat, and any other volumetric heat source, which is defined as

$$
h=\sum_{j} Y_{j} h_{j},
$$

where $Y_{j}$ is the mass fraction of component $j$. 
$h_{j}=\int_{T_{r e f}}^{T} c_{p, j} d T+H_{j}^{0}\left(T_{r e f, j}\right)$,

where $H_{j}^{0}\left(T_{r e f, j}\right)$ is the generation of component $j$ at a reference temperature of $j$, and $T_{r e f}$ is $298 \mathrm{~K}$.

(2) Liquid flow field control equation

Droplet particle motion equation: A discrete model is often used to describe the particle morphology and movement law of the gaseous material accounting for a very small proportion of the total volume. The droplets formed by the shower account for much less than $10 \%$ of the volume in the flow field of the tower. Therefore, a discrete model can be reasonably used to describe the droplet trajectory. This model can describe the movement of droplets in Lagrangian coordinates, fully consider the interaction between particles and smoke, and accurately predict the droplets in the flow. Inside the desulfurization spray tower, the trajectory and change of each droplet are not the same. Thus, they cannot be tracked in numerical simulations. Only a certain number of droplets are considered. Each of these droplets represents the same droplet. The tracking of the droplets with a certain scale for each orbital calculation represents a certain number of clusters of droplets. The discrete phase of motion has good properties. The orbital model applied to the method determined in Fluent is as follows: the Eulerian coordinate system is used in the prediction of the continuous fluid phase, whereas Lagrangian processing is used for the orbital motion characteristics of a large number of particles.

The droplets in the flow field are subjected to various forces. The gravity and resistance forces acting on the droplets are mainly analyzed. In accordance with the force condition of the particle in the fog effect of the smoke movement, the control equation of the droplet trajectory is

$$
\frac{d u_{p}}{d t}=F_{D}\left(u_{g}-u_{p}\right)+\frac{g\left(\rho_{p}-\rho_{g}\right)}{\rho_{p}},
$$

In Equation (1-11), $F_{D}\left(u_{g}-u_{p}\right)$ is the unit mass resistance that the droplets receive in the meteorological flow field. Its expression is

$$
F_{D}=\frac{18 \mu}{\rho_{p} d_{p}^{2}} \frac{C_{D} \operatorname{Re}}{24},
$$

where Re is the relative Reynolds number defined as

$$
\operatorname{Re}=\frac{\rho_{g} d_{p}\left|u_{p}-u_{g}\right|}{\mu} .
$$

In Equation (1-12), $C_{D}$ is determined by

$$
C_{D}=\frac{24}{\operatorname{Re}}\left(1+b_{1} \operatorname{Re}^{b_{2}}\right)+\frac{b_{3} \operatorname{Re}}{b_{4}+\operatorname{Re}},
$$

where the constants are

$$
\begin{aligned}
& b_{1}=\exp \left(2.3288-6.4581+2.4486 \phi^{2}\right), \\
& b_{2}=0.0964+0.5565 \phi, \\
& b_{3}=\exp \left(4.905-13.8944 \phi+18.4222 \phi^{2}-10.2599 \phi^{3}\right), \\
& b_{4}=\exp \left(1.4681+12.2584 \phi-20.7322 \phi^{2}+15.8855 \phi^{3}\right) .
\end{aligned}
$$

In Equations (1-15)-(1-18), the non-equivalent factor can be defined as $\phi=s / S$, where $s$ is the surface area of the 
ideal sphere with the same particle size and $S$ is the actual surface area of the particles. Here, the effect of smoke flow on the motion of the discrete droplets needs to be analyzed.

Droplet particle size distribution: The calculation of the two-phase gas-liquid flow is largely related to the distribution of droplet sizes. The diameters of the droplets in the spray tower can reach a minimum of $0.2 \mathrm{~mm}$, whereas the coarser droplets can have a diameter of $5 \mathrm{~mm}$. The Rosin-Rammler model is a mathematical model that describes particle size distribution. This model can accurately represent the distribution of fine particles, such as droplets, and calculate droplet trajectory. Here, the particle size distribution provided by the manufacturer is fitted to the RosinRammler distribution curve. Accordingly, the correlation coefficient is solved, and the function parameters are set.

$$
Y_{d}=\exp \left[-(d / \bar{d})^{n}\right]
$$

where $d=0.003696$ and $n=1.51$ in accordance with the nozzle test data of the manufacturer.

(3) Droplet and gas phase coupling

Momentum exchange: To realize the calculation of the coupling of the gas and liquid phases, the force of interaction between them should be considered. This force is represented by

$$
F=\sum\left[F_{D}\left(u_{g}-u_{p}\right)+F_{O}\right] m_{p} \Delta t
$$

where $F$ is the force between the particles and gas phase, $\mathrm{N} ; F_{0}$ is another unit mass force, $\mathrm{N} / \mathrm{kg} ; m_{\mathrm{p}}$ is the liquid mass flow rate, $\mathrm{kg} / \mathrm{s} ; \Delta \mathrm{t}$ is the time step, $\mathrm{s}$.

Energy exchange:

$$
Q=\left[\frac{\overline{m_{p}}}{m_{p, 0}} c_{p} \Delta T_{p}+\frac{\Delta m_{p}}{m_{p, 0}}\left(-h_{f j}+h_{p y r o l}+\int_{T_{r e f}}^{T_{p}} c_{p, i} d T\right)\right] m_{p, 0}^{-},
$$

where $h_{f i}$ is the latent heat during the volatile separation, $\mathrm{J} / \mathrm{kg} ; \overline{m_{p}}$ is the average mass of the controlled particles, $\mathrm{kg} ; C_{\mathrm{p}}$ is the specific heat capacity of the particles, $\mathrm{J} /(\mathrm{kg} \cdot \mathrm{K}) ; M_{\mathrm{p}, 0}$ is the initial particle quality, $\mathrm{kg} ; \Delta T_{p}$ is the change in the temperature of the controlled particles in the body, $\mathrm{K}$;

$h_{p y r o l}$ is the amount of heat required for pyrolysis at the time of volatile separation, $\mathrm{K} ; c_{p, i}$ is the specific heat capacity of the controlled particles during volatile separation, $\mathrm{J} /(\mathrm{kg} \cdot \mathrm{K}) ; \Delta m_{p}$ is the mass of the controlled particles, $\mathrm{kg}$; $T_{p}$ is the outlet temperature of the controlled particles, $\mathrm{K} ; T_{r e f}$ is the corresponding reference temperature, $\mathrm{K}$;

$m_{p, 0}^{-}$is initial mass flow rate of the tracked particles, $\mathrm{kg} / \mathrm{s}$.

Mass exchange: When the number of particles passing through each model is controlled, the quality of the discrete phases is calculated by the change in the mass of the particles. The change in particle mass can be expressed as

$$
M=\frac{\Delta m_{p}}{m_{p, 0}} \cdot m_{p, 0}^{-}
$$

\section{RESULTS AND DISCUSSION}

In this study, different entry modes of flue gas, different spray configurations, and different deflector settings are simulated.

\subsection{Different inlet modes}

Figure 2 shows the system diagram of the model. According to the actual flue gas pipeline laying, the flue gas is defined along the direction of tower axis and the horizontal direction perpendicular to the axis in this case, which means the flue gas is along the $\mathrm{X}$ axis and the $\mathrm{Z}$ axis direction, whereas the latter corresponds to the top intake mode and side air inlet mode. 
In the top inlet intake mode (Fig. 3), in which $90^{\circ}$ from the $X$-axis is the reference inlet angle, the flue gas flow is investigated. The effects of other inlet angles from the $X$-axis, including $75^{\circ}, 60^{\circ}, 45^{\circ}, 30^{\circ}, 15^{\circ}$, and $0^{\circ}$, are also examined.

In the side inlet intake mode (Fig. 4), in which the inlet is $90^{\circ}$ from the $X$-axis and $0^{\circ}$ from the $Z$-axis is the reference inlet angle, the flue gas flow is investigated. The effects of other inlet angles from the $Z$-axis including $15^{\circ}$, $30^{\circ}, 45^{\circ}, 60^{\circ}$, and $75^{\circ}$ are also taken into account. Subsequently, the flow field, pressure loss, and other factors were analyzed by numerical simulation. The characteristics and advantages of the two inlet modes were compared.

\subsubsection{Flow field analysis}

Fig. 3 shows the flow field at different angles of the top inlet. The figure shows that the variation in the angles exerts a significant effect on the flow field of the flue gas. When $\varphi=0^{\circ}, 15^{\circ}$ and $30^{\circ}$, the tower presents two distinct air vortex areas, and the flue gas is not dispersed well in the tower. When it flows into the stock, the space within the tower is not maximized. The flue gas flow in the tower is not smooth. This type of flow is inconducive to the desulfurization reaction. When $\varphi=45^{\circ}, 60^{\circ}$ and $70^{\circ}$, the flue gas is sideling into the tower. Although the flue gas is dispersed in all directions under the pressure of the tower wall and the liquid resistance, the development of flue gas is still insufficient. Most of the flue gas is distributed close to the slurry surface, whereas only a small portion of the gas flows to the upper half of the space. When $\varphi=45^{\circ}$, the flue gas dispersion is relatively uniform, making full use of tower space.

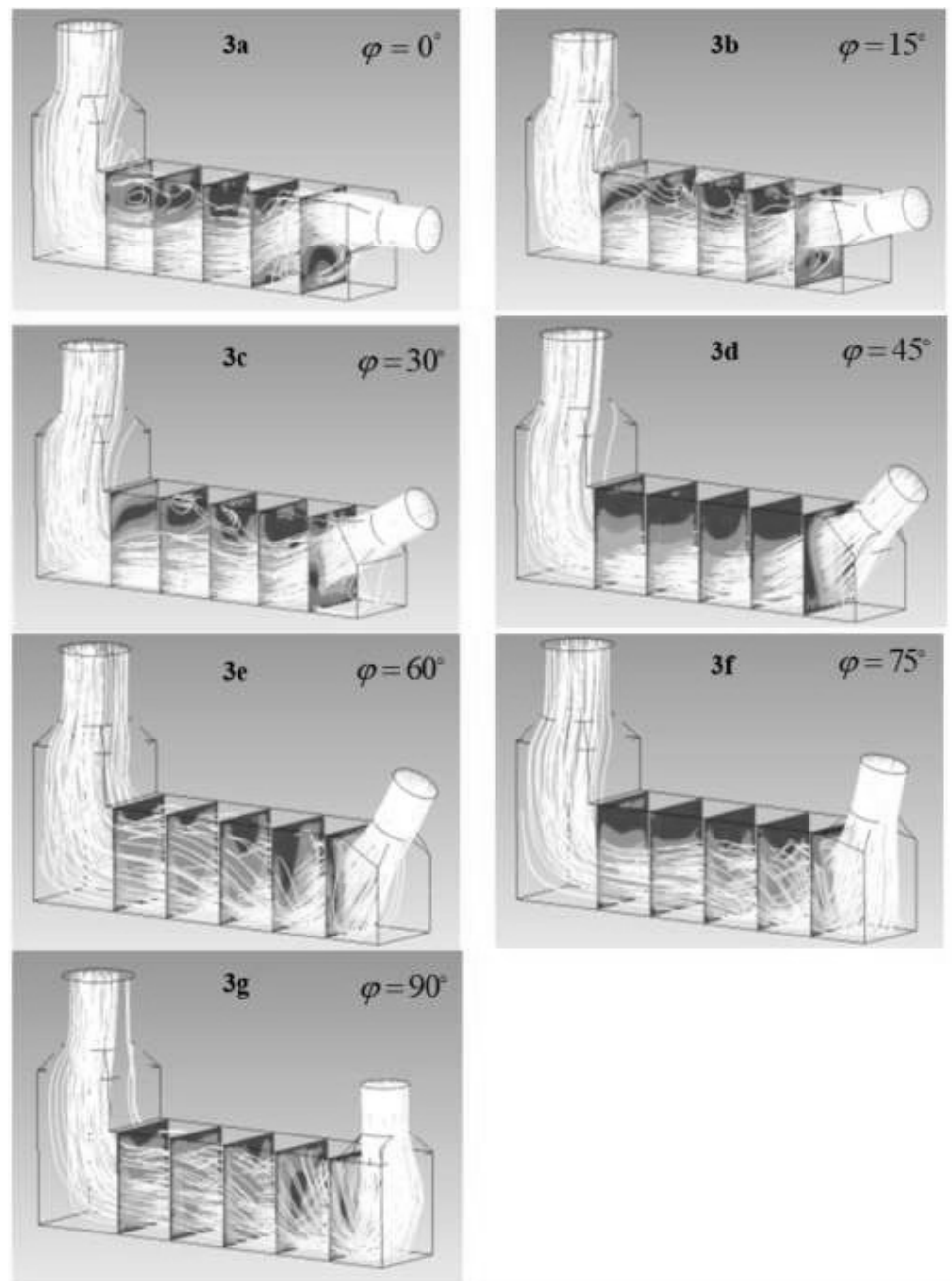

Figure 3. Different angles of top intake. 
Fig. 4 shows the diagrams of the side inlet flow fields at different angles. The flue gas entering the tower on the side directly impacts the tower wall and then disperses in the remaining parts of the tower. When the angle is small, the flue gas is close to the opposite side of the tower wall. As the angle increases to $90^{\circ}$, the effect gradually weakens, and the gas is dispersed in the tower uniformly. This condition is conducive to gas and liquid contact.
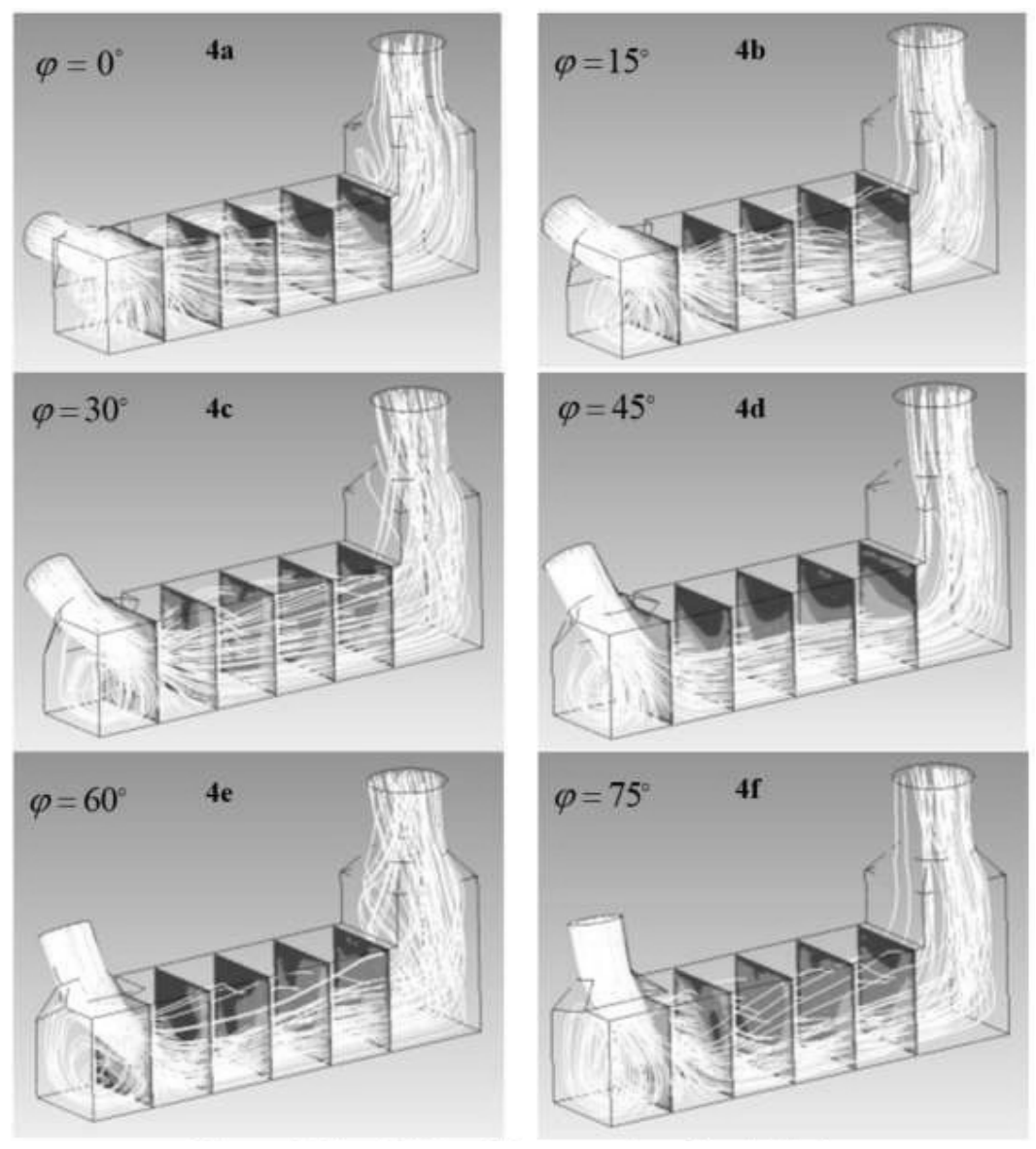

Figure 4. Flow field at different angles of the side inlet.

\subsubsection{Pressure loss}

Fig. 5 shows the pressure loss of different inlet modes. The pressure loss between the inlet and outlet of the desulfurization tower is simulated in different inlet modes. In the top inlet intake mode, the pressure loss increases with the increase in the angle when the angle is less than $45^{\circ}$. When the angle is more than $45^{\circ}$, the pressure loss is more than $70 \mathrm{~Pa}$, which is remarkably higher than that when the angle is $45^{\circ}$. The minimum pressure loss $(62.78 \mathrm{~Pa})$ is achieved when the angle is $45^{\circ}$. At angles less than $45^{\circ}$, the variation in pressure loss is minimal. The order (from highest to lowest) of pressure losses is $90^{\circ}>75^{\circ}>60^{\circ}>0^{\circ}>15^{\circ}>30^{\circ}>45^{\circ}$. In the side inlet intake mode, the pressure loss is the least when the angle is $0^{\circ}$, reaching only $76.97 \mathrm{~Pa}$. The pressure losses at other angles are approximately $95 \mathrm{~Pa}$. The order of pressure losses is $75^{\circ}>60^{\circ}>45^{\circ}>30^{\circ}>15^{\circ}>0^{\circ}$. 


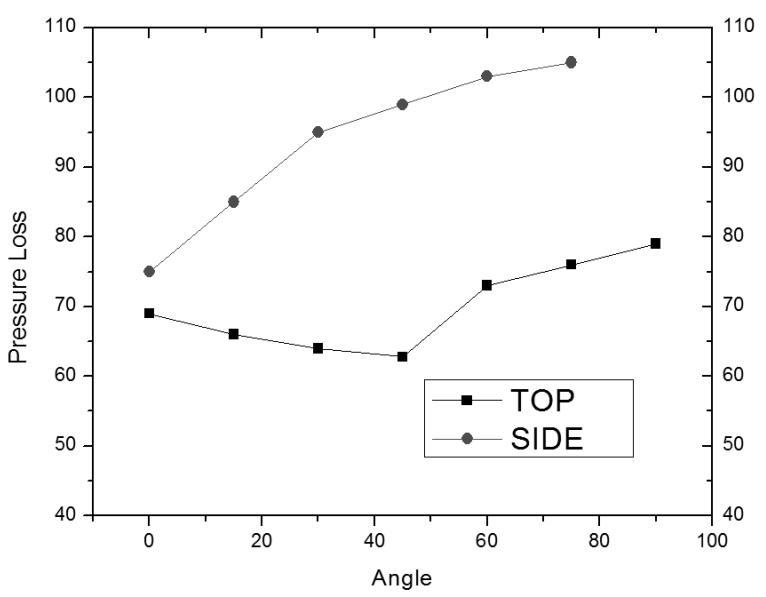

Figure 5. Pressure loss in different inlet modes.

\subsubsection{Spray zone residence time}

The flue gas residence time is defined as the time at which the flue gas microelement moves from the inlet to the outlet. Fig. 6 shows a comparison of the average residence times of the flue gas in the spray area in different inlet modes. In the top inlet intake mode, the average residence time decreases first and then increases with the increase in angle. When the inlet angle is $30^{\circ}$, the average residence time is the shortest $(3.30 \mathrm{~s})$. As the angle increases, the average residence time is gradually extended. When the inlet angle is increased to $90^{\circ}$, the average residence time reaches its maximum of $5.45 \mathrm{~s}$. The order of residence times is $90^{\circ}>60^{\circ}>75^{\circ}>0^{\circ}>45^{\circ}>15^{\circ}>30^{\circ}$. In the side inlet intake mode, the longest average residence time is $5.39 \mathrm{~s}$ at an inlet angle of $30^{\circ}$. The average residence times of the other angles show remarkable differences. The order of residence times is $30^{\circ}>0^{\circ}>60^{\circ}>75^{\circ}>15^{\circ}>45^{\circ}$.

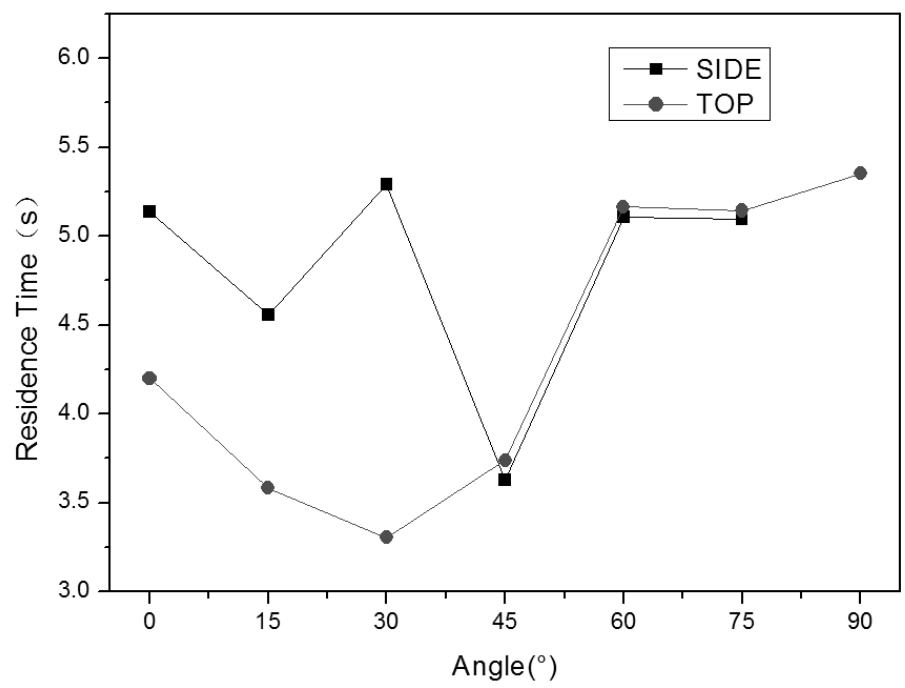

Figure 6. Effect of inlet mode on gas-liquid contact time.

\subsubsection{Turbulence intensity}

Turbulence intensity is equal to the ratio of turbulence pulsation velocity to the mean velocity, which is the relative index for measuring the strength of turbulence. As the turbulence intensity increases, the gas-liquid contact, gasliquid mass transfer effect, and desulfurization efficiency are improved (Meikap et al., 2002; Guo et al., 2008). Here, 
five cross-sections, which are 4, 5, 6, 7, and $8 \mathrm{~m}$ from the bottom of the tower height, are simulated to compare the average cross-sectional turbulence intensities.
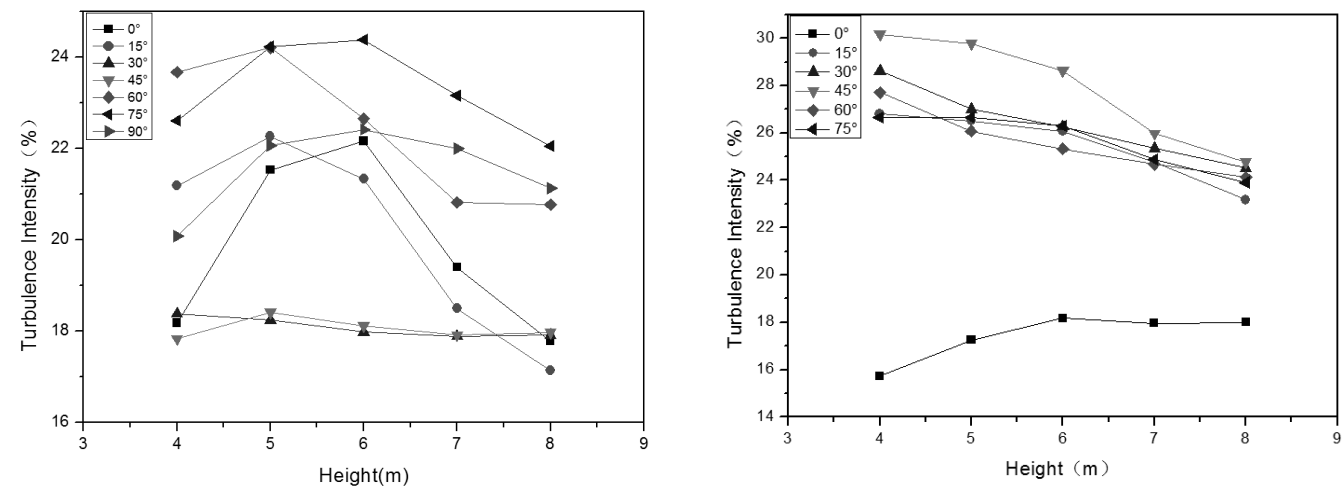

Figure 7. Top inlet turbulence intensity distribution. Figure 8. Side inlet turbulence intensity distribution.

Fig. 7 shows a comparison of the results of turbulence intensity in the top inlet intake mode. The trends of the turbulence intensities when the angles are $90^{\circ}, 75^{\circ}, 45^{\circ}$, and $30^{\circ}$ are approximately the same, indicating a uniform distribution of the flow field. The turbulence intensities at $90^{\circ}$ and $75^{\circ}$ are relatively large. At such intensities, the gas turbulence is enhanced, and slurry contact is relatively frequent. At $0^{\circ}$, the turbulence intensities at $5 \mathrm{~m}$ and 6 $\mathrm{m}$ are significantly higher than those at 4,7 , and $8 \mathrm{~m}$. This difference indicates the uneven distribution of flue gas, which hampers gas-liquid contact and decreases desulfurization efficiency. At $15^{\circ}$ and $60^{\circ}$, the flue gas concentration distributions at $4 \mathrm{~m}$ and $5 \mathrm{~m}$ are likewise inconducive to gas-liquid contact.

Fig. 8 shows the turbulence intensity distribution in the side inlet intake mode. At $0^{\circ}$, the most uniform turbulence intensity distribution is achieved, but the overall turbulence intensity maintains a slightly low level. At other angles, the turbulence intensity distributions show high values at the bottom and low values at the top. These results indicate that the flue gas is mainly distributed in the bottom layer and that less flue gas passes through the upper space. This condition forms an empty layer, which is inconducive to the full use of tower space. Similar results are shown in Fig. 4.

In summary, having all the indicators optimal at the same time is impossible, but the operation scheme can be selected based on the need. For example, if the efficiency and the economic indicators are the first-order priorities, then an inlet angle of $75^{\circ}$ is desirable in the top inlet intake mode. However, the gas-liquid contact time is nearly the longest, and the turbulence intensity along the vertical axis is evenly distributed under this condition. In the side inlet intake mode, $30^{\circ}$ can perform better.

\subsection{Different spray configurations}

After the tower shape and the inlet mode have been determined, the effect of spray configuration as an important parameter affecting the process is examined. The components of spray configuration include spray cone angle, spray height, and spray direction (Li et al., 2014). The nozzles used in most of the existing wet spraying technologies adopt spiral nozzles, with which the sprayed droplets form a solid cone. The spray cone angle is the size of the cross-section of the solid cone. The height of the spray is defined as the height of nozzle installation. The jet direction refers to the direction of the central axis of the solid cone, which actually represents the orientation of the nozzle. The direction vector is denoted by $(X, Y, Z)$.

\subsubsection{Effects of different spray cone angles}

The commonly used spray cone angle is between $60^{\circ}$ and $120^{\circ}$. A larger nozzle pressure is needed for a larger cone angle. In other words, the use of a powerful slurry circulation pump can increase pressure and energy consumption. The default jet direction is set at $30^{\circ}$ down from the vertical direction, and the spray height is $0.1 \mathrm{~m}$ from the top surface; that is, the spray height is $9.7 \mathrm{~m}$ from the ground. 


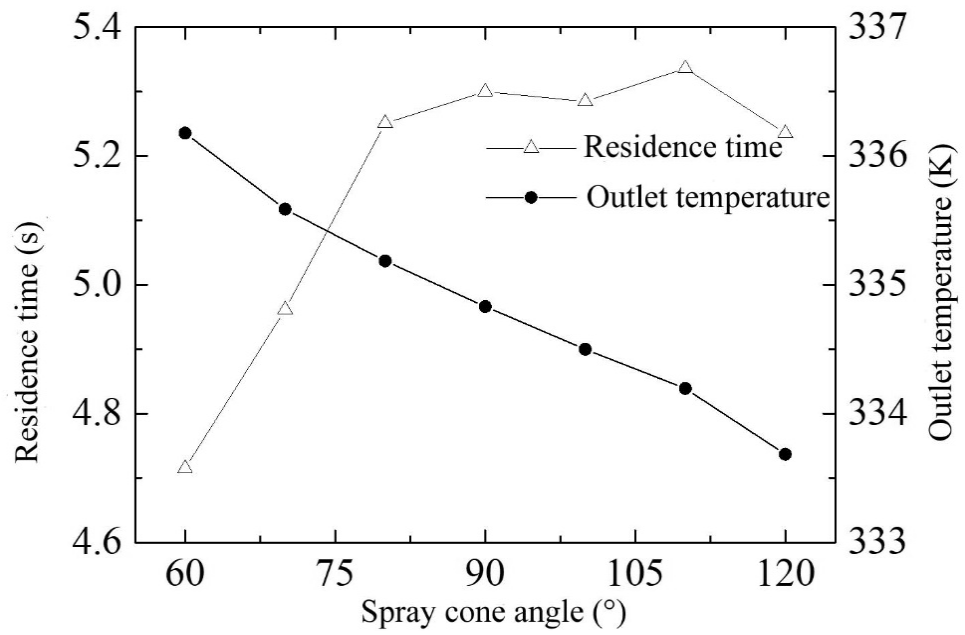

Figure 9. Relationships of spray cone angle to average outlet flue gas temperature and flue gas residence time.

Fig. 9 shows the relationship between the spray cone angle and the outlet flue gas temperature. As the spray cone angle increases, the average flue gas temperature at the outlet decreases, indicating that a larger spray cone angle favors droplet dispersion and full gas-liquid contact. Fig. 9 also shows the relationship between spray cone angle and smoke residence time if the total length of the spray zone in the tower is $22 \mathrm{~m}$. The total length of the spray zone is divided by the relative velocity of $X$ in the flue gas to obtain the residence time of the flue gas in the spray zone, which can be defined as the stay time. When the angle is less than $90^{\circ}$, increasing the nozzle cone angle can significantly extend the residence time, but increasing the angle blindly does not always yield favorable results. When the angle exceeds $90^{\circ}$, the time extension effect becomes unremarkable. The optimum spray cone angle is $110^{\circ}$.

\subsubsection{Effects of different spray heights}

The actual top height of the physical model in this study is $9.8 \mathrm{~m}$. In practice, a low spray height can cause a spray dead angle. Therefore, the spray heights in the simulation experiments are 9.7, 9, and $8 \mathrm{~m}$, which are $0.1,0.8$, and 1.8 $\mathrm{m}$ from the top surface, respectively. The spray cone angle is $90^{\circ}$, and the spray direction is at an angle of $45^{\circ}$ to the vertical downward direction.

Fig. 10 shows the relationship between the spray height and the outlet flue gas temperature. The outlet flue gas temperature is the lowest, and the gas-liquid contact is optimum when the distance is $0.8 \mathrm{~m}$ from the top surface. When the spray is farther away from the top surface, the outlet flue gas temperature rises significantly. This outcome may be attributed to the formation of more spray dead corners, especially in the top area. This part of the smoke cannot establish contact with the shower liquid, resulting in a "short-circuit smoke." If the spray height is too high, then the contact of the spray droplets at the bottom of the air flow will be insufficient, the heat exchange at the bottom of the air flow will be insufficient, and the overall outlet smoke temperature will increase. Fig. 11(a) shows a cross-section of the smoke temperature distribution in the tower when the spray height is $0.1 \mathrm{~m}$ from the top surface. The smoke temperature at the bottom is higher than the smoke temperature at the top. The bottom flue gas, which causes a high temperature, passes directly through the spray zone and mixes with the rest of the flue gas; as a result, the average outlet flue gas temperature increases. This outcome is attributed to the liquid droplets falling to the bottom flue gas flow because of the excessively high spray position. During evaporation or when the temperature is close to the smoke temperature, the underlying gas flow is fast, and the contact is insufficient. Fig. 11(b) is a cross-section of the smoke temperature distribution in the tower when the height of the spray is $0.8 \mathrm{~m}$ from the top surface. The smoke temperature distribution in the tower is relatively uniform, and the smoke and liquid droplets in the upper and lower layers have enhanced contact. Fig. 11(c) is a cross-section of the smoke temperature distribution in the tower when the spray height is $1.8 \mathrm{~m}$ from the top surface. The smoke temperature at the top of the tower is higher than that in the 
middle layer, and the spray angle is high at the top. The top of the flue gas cannot fully function with the droplets and is directly discharged through the tower body.

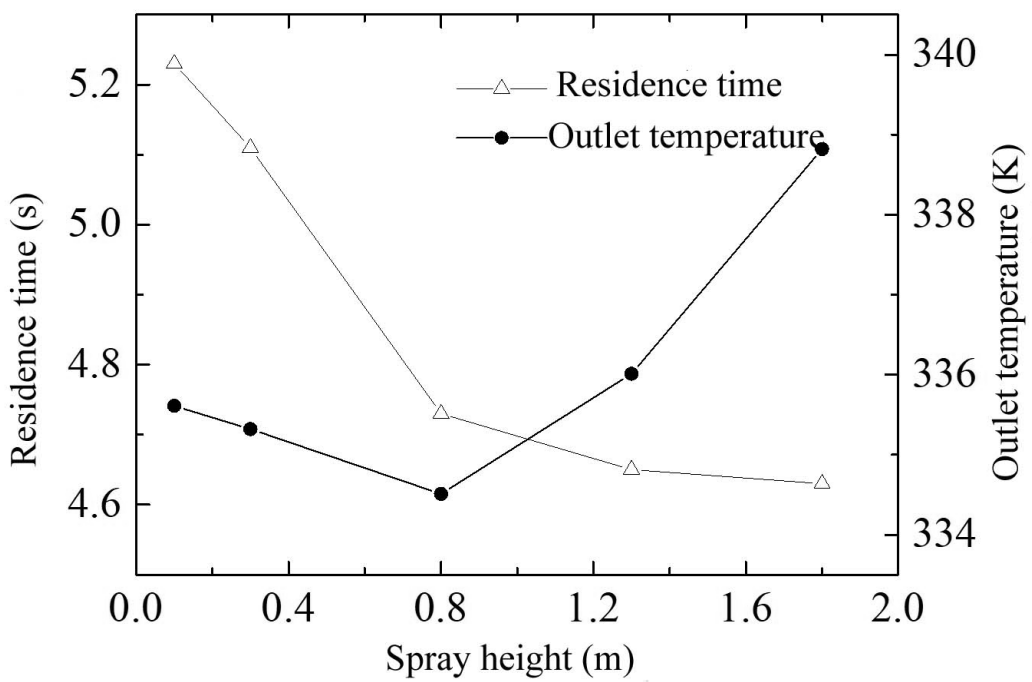

Figure 10. Relationships of spray height to average outlet flue gas temperature and flue gas residence time.

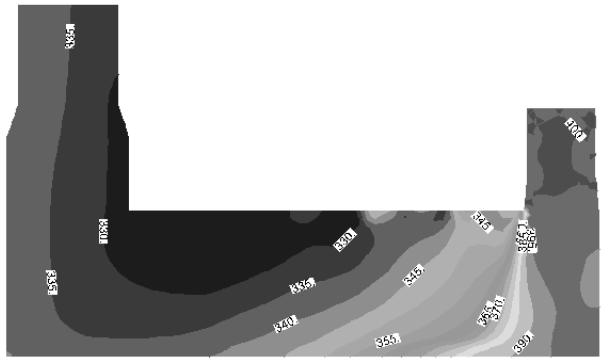

(a) $0.1 \mathrm{~m}$ from the top of the tower

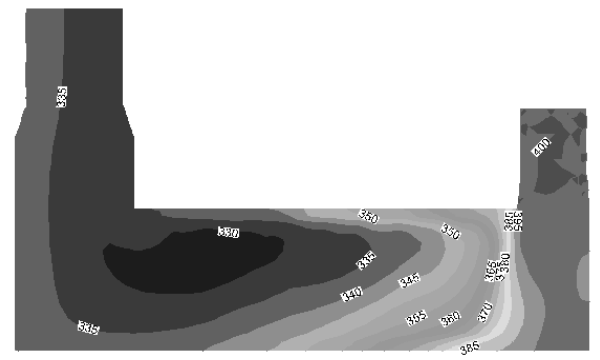

(b) $0.8 \mathrm{~m}$ from the top of the tower

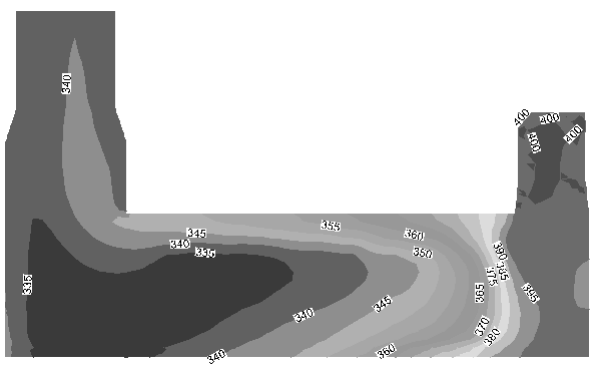

(c) $1.8 \mathrm{~m}$ from the top of the tower

Figure 11. Spray height and smoke temperature distribution cloud diagrams.

\subsection{Comparison of the baffle plates assembling}

The reasonability of the flow field distribution of the horizontal desulfurization tower is related to the improvement in the desulfurization efficiency and the reduction in the pressure loss of the absorption tower. Previous studies (Yang, 2017) have indicated that the main optimization measures for the flow field in the tower are changing the geometry of the inlet and adding internal deflectors in the tower. In this section, based on the existing experience with diversion 
arrangement in engineering combined with the actual conditions of the model, a deflector plate type is set up, and its function and effect are analyzed through numerical simulation. The deflector plate type model is compared with the no-diversion plate model. The distribution of the flow field can provide a reference for engineering practice. The layout of the baffles or deflector is shown in Fig. 12.

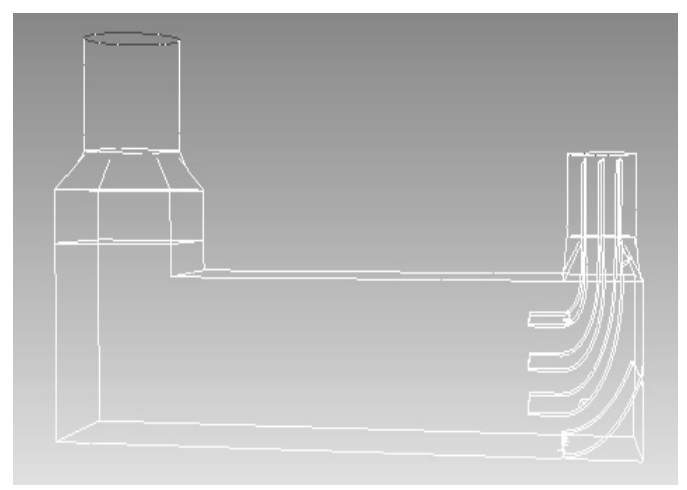

Figure. 12. Arrangement of the deflector.

\subsubsection{Flow field distribution}

Fig. 13(a) shows the flow field distribution before adding the deflector, whereas Fig. 13(b) shows the flow field distribution after adding the deflector. An intersecting surface is added at $6,10,14$, and $8 \mathrm{~m}$ after entering the tower. A cross-section is made, and contour maps of speeds are made on each section. The velocity cloud diagram shows that before the deflector is added, the smoke distribution is very uneven, and the larger part of the smoke flows close to the tower wall. According to a previous study, the flue gas attached to the wall cannot be fully reflected because of the small spray coverage around the tower wall and the low slurry density. The $\mathrm{SO}_{2}$ contained therein will also be discharged out of the tower without being fully absorbed, thereby reducing the overall system desulfurization efficiency. With the addition of the deflector, the distribution of the flue gas becomes evenly distributed in the transverse direction, and the streamline along the tower becomes smooth and even. Under this condition, the flue gas adherence flow can be reduced, and the flue gas and the spray slurry can establish contact. As a result, the two-phase gas-liquid mixing becomes uniform, the mass-to-phase mass transfer efficiency is enhanced, and the desulfurization efficiency is improved. After the deflector is added, the flue gas in the tower space becomes full and saturated, and the spray space in the tower is fully utilized. This outcome shows that the deflector presents a certain rectification effect such that the distribution of the flow field of the flue gas achieves enhanced uniformity. This condition is beneficial to the stability of the flow field in the tower and the uniform distribution of the turbulent slurry spray. Thus, the deflector can enhance the mass transfer and increase the desulfurization efficiency.

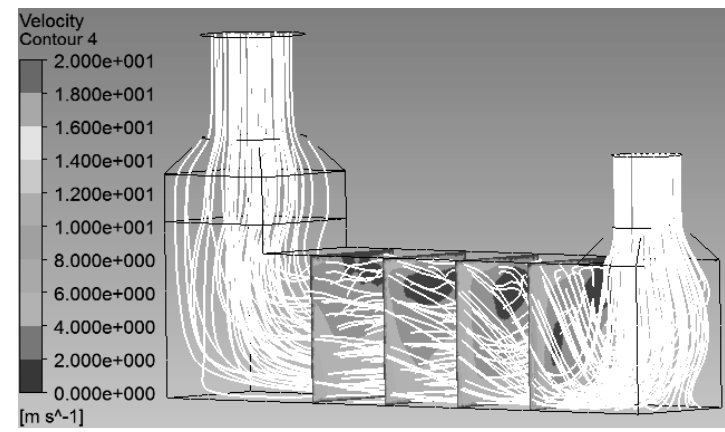

(a) No added deflector flow field

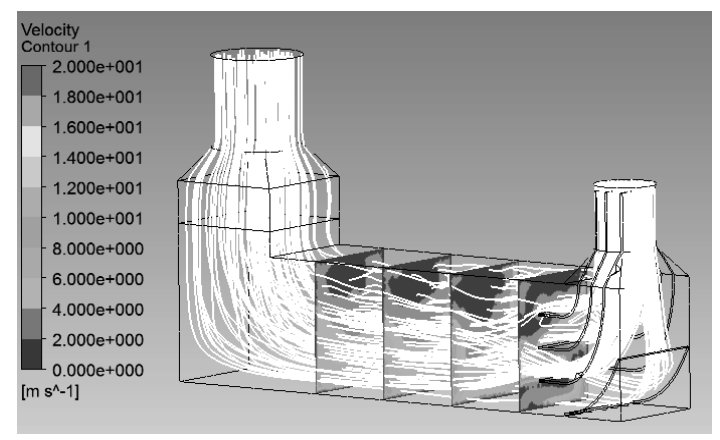

(b) With deflector flow field

Figure 13. Flow field distributions before and after adding a deflector. 


\subsubsection{Pressure loss situation}

Before the deflector is added, the pressure difference between the inlet and the outlet is $246 \mathrm{~Pa}$. After the deflector is added, the pressure difference between the inlet and the outlet is $371 \mathrm{~Pa}$; the pressure difference increases by $125 \mathrm{~Pa}$. Fig. 14 is a pressure cloud diagram in the middle section of the tower before and after the baffle is added. Fig. 14(a) shows that if the deflector is not added, then a large pressure concentration area will exist at the bottom of the inlet and outlet. This pressure concentration area is due to the direct impact of the air flow in the tower, reflecting that the air flow is not smooth in this case. The corners gather and form whirlpools, which are inconducive to gas-liquid mass transfer and desulfurization reactions. By contrast, the pressure cloud diagram in Fig. 14(b) shows that the pressure changes are evenly stratified, suggesting that the flow field in the tower is smooth. Furthermore, a large vortex area does not exist, and the lower outlet is also a pressure concentration area, indicating that the air flow in the area is smooth.

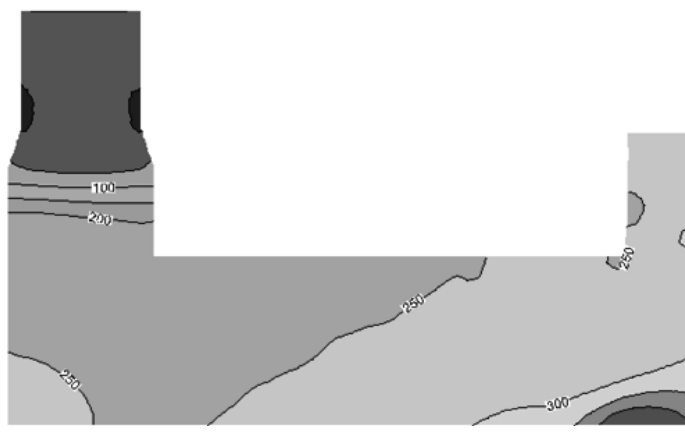

(a) Pressure cloud diagram without deflector

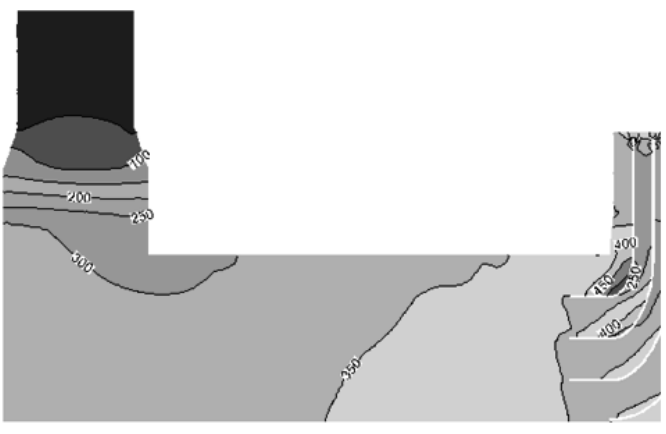

(b) pressure cloud diagram with deflector

Figure 14. Pressure clouds before and after adding the deflector.

\subsubsection{Temperature distribution}

Before the deflector is added, the temperature of the flue gas outlet is $335 \mathrm{~K}$. After the deflector is added, the flue gas temperature drops significantly and becomes $325 \mathrm{~K}$, which is close to the temperature of the spray liquid, indicating that the flue gas rectification effect of the deflector is considerable. The gas-liquid contact effect and heat transfer effect are enhanced. Fig. 15 shows the temperature cloud diagrams of the flue gas in the middle section of the tower before and after the deflector is add ed.

A comparison of Fig. 15(a) and 15(b) shows that, without the deflector, the airflow is very turbulent after passing through the spray area, the top and bottom flow phenomena are very serious, and the top and bottom of the tower are sprayed. The areas where the leaching effect is the weakest result in the insufficient contact between the airflow and the spray liquid in the two areas and the high temperature of the smoke. When the baffle is added, the flue gas is rectified by the baffle plate and evenly distributed in the spray area, the space utilization rate is high, the flue gas adherence on top at the bottom is weakened, the contact with the spray droplet is relatively sufficient, and the heat and mass transfer effect is achieved. More importantly, the exit smoke temperature naturally decreases. 


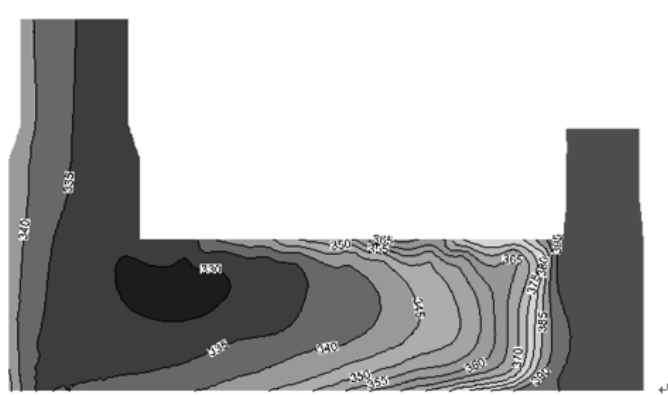

(a) Temperature cloud diagram without deflector

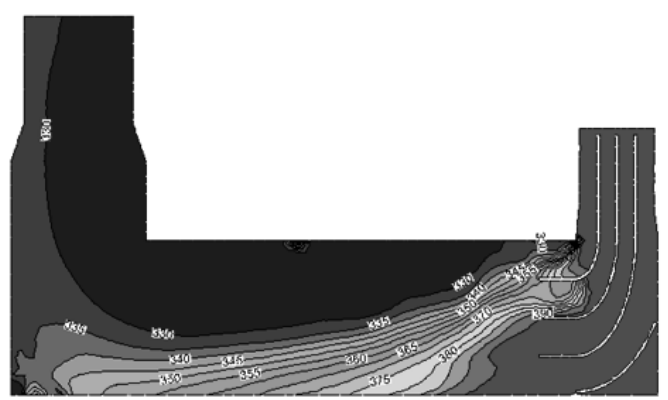

(b) Temperature cloud diagram with deflector

Figure 15. Temperature cloud before and after adding the deflector.

\section{CONCLUSIONS}

(1) A horizontal column technology has changed the traditional gas-liquid reverse contact mode. The flow field in the spray tower can be numerically simulated by CFD technology. The numerical results can reflect the gas and liquid flows in the spray tower. These results can provide theoretical support for the optimization of the structure of the spray tower.

(2) The inlet method exerts an important effect on the flue gas flow field of the horizontal tower. In the top inlet intake mode, the pressure loss is the lowest (approximately $62.78 \mathrm{~Pa}$ ) when the angle is $45^{\circ}$. When the inlet angle is increased to $90^{\circ}$, the average residence time reaches a maximum of $5.45 \mathrm{~s}$. In the side inlet intake mode, the pressure loss is $76.97 \mathrm{~Pa}$ when the angle is $0^{\circ}$. The average residence time is the longest $(5.39 \mathrm{~s})$ at an inlet angle of $30^{\circ}$.

(3) When efficiency is taken as the first-order priority and the economic indicator is also taken into account, an inlet angle of $75^{\circ}$ is recommended in the top inlet intake mode, whereas an inlet angle of $30^{\circ}$ performs the best in a side inlet intake mode.

(4) The spray configuration exerts an important influence. Under the process conditions investigated in this study, when the spray cone angle is $110^{\circ}$ and the installation height is controlled at $0.8 \mathrm{~m}$ from the top surface, the smoke residence time is long, and the contact is sufficient.

(5) Under the process conditions studied, adding a reasonable deflector is favorable. Although minimal pressure loss is added, the flue gas rectification effect is remarkable, the flue gas traces in the tower is smoothened, the distribution becomes uniform, and the local eddy and energy loss are reduced. Furthermore, the improved gas-liquid contact can promote the occurrence of desulfurization reactions.

\section{ACKNOWLEDGMENT}

National Key R\&D Program of China (2017YFC0210301), National Science Foundation for Young Scientists of China(No. 21707007), National Natural Science Foundation of China (No. 51774038) and Beijing Nova Program (Z171100001117084) are acknowledged.

\section{REFERENCES}

Calautit, J.K. \& Hughes, B.R. 2014. Wind tunnel and CFD study of the natural ventilation performance ofa commercial multidirectional wind tower. Building \& Environment, 80(10): 71-83.

Du, Y.G., Deng, J.J. \& Feng, Z.Y., 2010. Design and optimization of wet flue gas desulfuration system. Environmental Engineering, 28(2): 69-77.

Fan, Y.L., Zheng, P.H., Wang, P., Tan, G.Z., Shen, J.T. \& Liu, C. 2017. The Technology of Sintering Flue Gas Desulfurization 
Technology is Discussed. Chemical Engineering Design Communications, 43(8): 198-202.

Guo, R.T., Gao, X., Ding, H.L. \& Luo, Z.Y. 2008. Study on flow field optimization in wet flue gas desulfurization spray scrubber. Proceedings of the CSEE, 28(29): 70-77.

Li, S.H., Ma, W.N. \& Wang, H. 2014. Numerical simulation for effect of nozzle angle on flow resistance in CFB-FGD. Chemical Industry \& Engineering Progress, 3: 590-596.

Liang, K., Peng, Z., Yuan, Z. \& Fan, F. 2007. Atomization and drop-size distribution of liquid-liquid systems. Journal OfChemical Industry and Engineering, 58(8): 1935-1942.

Liu, Z., Zhang, Y.G., Han, B., Tan, Z.C. \& Li, Q.H. 2018. Advances in $\mathrm{SO}_{2}$ and $\mathrm{NOx}$ emission control for Chinese iron and steel industries. Przemysl Chemiczny, 97(3): 473-480.

Marocco, L. 2010. Modeling of the fluid dynamics and $\mathrm{SO}_{2}$ absorption in a gas-liquid reactor. Chemical Engineering Journal, 162(1): 217-226.

Meikap, B.C., Kundu, G. \& Biswas, M.N. 2002. Modeling of a novel multi-stage bubble column scrubber for flue gas desulfurization. Chemical Engineering Journal, 86(3): 331-342.

Nygaard, H.G., Kiil, S., Johnsson, J.E., Jensen, J.N., Hansen, J. \& Fogh, F. 2004. Full-scale measurements of $\mathrm{SO}_{2}$ gas phase concentrations and slurry compositions in a wet flue gas desulphurisation spray absorber. Fuel 83(9): 1151-1164.

Song, H., Wang, X. \& Zhao, X. 2009. Progress in wet flue gas desulfurization technology. Chemical Industry \& Engineering, 26(5): 455-459.

Wei, S.J., Wang, S. \& Zhou, R. 2014. Research on present situation of desulfurization and denitrification technology for sintering flue gas. Environmental Engineering, 2: 95-97.

Wen, R.G., Liu, K.J. \& Wei, J.C. 2015. Numerical simulation on gas-liquid two-phase flow in desulfurization tower of sintering flue gas ammonia process. Computer Aided Engineering, 4: 72-76.

Yang, L. 2017. Numerical Simulation Study on Separation Characteristics of Baffle Plate Demister. Technology \& Development of Chemical Industry, 7: 16-20.

Zhan, J.C., Ran, J.Y. \& Sun, T.X. 2008. Numerical simulation and experimental study on desulfurization process in FGD absorbers. Journal of Power Engineering, 28(3): 433-437.

Zhou, S., Jin, B., Zhong, Z. \& Sun, K. 2005. Flow simulation for large scale FGD scrubbers and optimization design. Journal of Southeast University (Natural Science Edition), 20(1): 105-110.

Submitted: $20 / 06 / 2018$

Revised: $\quad 25 / 08 / 2018$

Accepted: 30/08/2018 


\section{المحاكاة الرقمية لبرج الرش الأفقي الجمديد لإزالة الكبريت من غاز المداخن

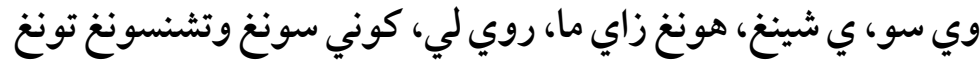

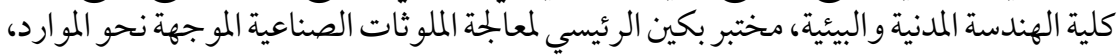

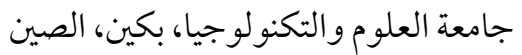

\section{الخلاصة}

يكن أن يتذبذب معدل دفق غاز المداخن ودرجة حرارته من ماكينة التبريد في نطاق واسع؛ وبالتالئي، ينبغي تشغيل أداة إزالة

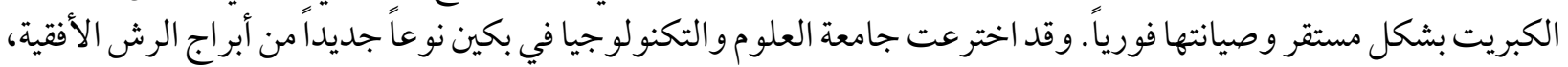

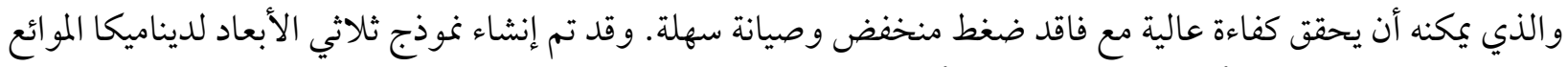

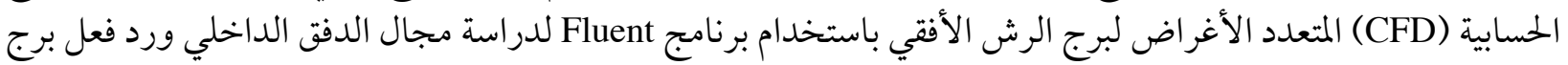

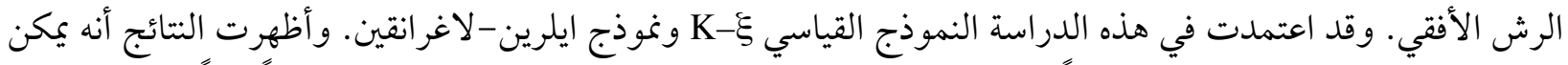

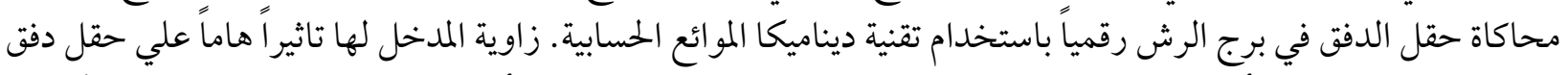

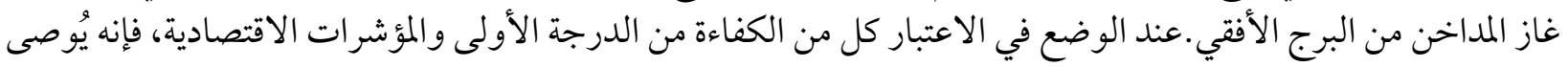

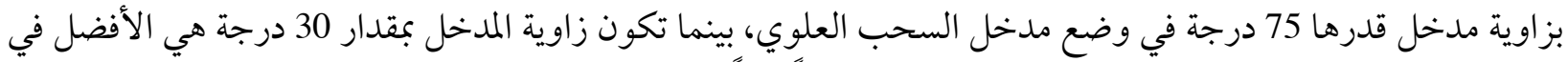

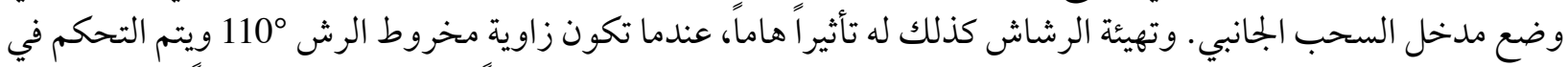

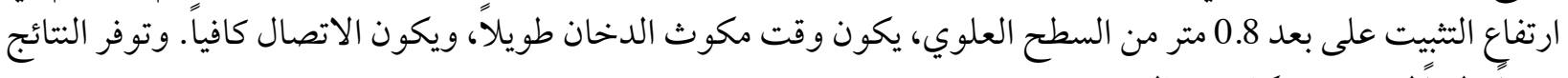
دعماً نظرياً لتحسين هيكل برج الرش بعد 